\title{
Clinicopathologic profile of gastrointestinal stromal tumors (GISTs) with primary KIT exon 13 or exon 17 mutations: a multicenter study on 54 cases
}

Jerzy Lasota ${ }^{1}$, Christopher L Corless ${ }^{2,3}$, Michael C Heinrich ${ }^{2,3}$, Maria Debiec-Rychter ${ }^{4}$, Raf Sciot $^{4}$, Eva Wardelmann ${ }^{5}$, Sabine Merkelbach-Bruse ${ }^{5}$, Hans-Ulrich Schildhaus ${ }^{5}$, Sonja E Steigen ${ }^{6}$, Jerzy Stachura ${ }^{7}$, Agnieszka Wozniak ${ }^{8}$, Cristina Antonescu ${ }^{9}$, Ondrej Daum ${ }^{10}$, Javier Martin ${ }^{11}$, Javier Garcia del Muro ${ }^{12}$ and Markku Miettinen ${ }^{1}$

${ }^{1}$ Department of Soft Tissue Pathology, Armed Forces Institute of Pathology, Washington, DC, USA; ${ }^{2}$ Department of Pathology and Division of Hematology and Oncology, Oregon Health \& Science University Cancer Institute, Portland, OR, USA; ${ }^{3}$ VA Medical Center, Oregon Health \& Science University, Portland, OR, USA; ${ }^{4}$ Department of Human Genetics, Catholic University of Leuven, Leuven, Belgium; ${ }^{5}$ Department of Pathology, University of Bonn Medical Center, Bonn, Germany; ${ }^{6}$ Department of Pathology, Hospital Northern Norway, Tromsø, Norway; ${ }^{7}$ Department of Pathology, Jagiellonian University, Krakow, Poland; ${ }^{8}$ Department of Biology and Genetics, Medical University of Gdansk, Gdansk, Poland; ${ }^{9}$ Department of Pathology, Memorial Sloan-Kettering Cancer Center, New York, NY, USA; ${ }^{10}$ Department of Pathology, Medical Faculty Hospital, Charles University, Plzen, Czech Republic; ${ }^{11}$ Department of Oncology, Hospital Universitario de Son Dureta, Palma de Mallorca, Spain and ${ }^{12}$ Instituto Catalana de Oncologia, Hospital Clinic Barcelona, Barcelona, Spain

Gastrointestinal stromal tumors (GISTs) are mesenchymal neoplasms driven by oncogenic, mutational activation of KIT or platelet-derived growth factor receptor $\alpha$ (PDGFRA). GIST-specific KIT or PDGFRA mutations have been linked to tumor location, tumor cell morphology and clinical behavior. The purpose of this study was to evaluate the clinicopathologic profile of GISTs that have KIT exon 13 or exon 17 mutations. Through the collaboration of several GIST research groups, we gathered 54 cases from the pre-imatinib era that had such primary mutations. From our observations and those in the literature, we estimate that the frequency of these mutations is no higher than $1-2 \%$. Almost all (32 of 33, 97\%) of the KIT exon 13 mutations were the 1945A $>$ G substitution leading to Lys642Glu. A majority (15 of $21,71.4 \%$ ) of the KIT exon 17 mutations were the 2487T $>$ A substitution leading to Asn822Lys. Demographic and clinicopathologic data were available for 26 and 14 KIT exon 13 and exon 17 mutant GISTs, respectively. Median age and male to female ratio were similar to ones reported in other GIST studies. Small intestinal tumors were two times more frequent than gastric ones among KIT exon 17 mutants. Also, intestinal tumors were slightly overrepresented among KIT exon 13 mutants when compared with population-based studies. The majority of $K I T$ exon 13 or exon 17 mutants had a spindlecell morphology and only a few had epithelioid features. Tumor size varied from 1.2 to $25 \mathrm{~cm}$ and average mitotic rates were 9.5 and 4.2 for KIT exon 13 and exon 17 mutants, respectively. Gastric KIT exon 13 mutant GISTs tend to be slightly larger and more aggressive than gastric GISTs in average, whereas the behavior of small intestinal GISTs with KIT exon 13 mutations does not differ from other small intestinal GISTs. The latter is also true for all KIT exon 17 mutant GISTs.

Modern Pathology (2008) 21, 476-484; doi:10.1038/modpathol.2008.2; published online 1 February 2008

Keywords: GIST; KIT; tyrosine kinase domain; mutation

Correspondence: Dr J Lasota, MD, Department of Soft Tissue Pathology, Armed Forces Insitute of Pathology, 6825 16th Street, N.W., Building 54, Washington, DC 20306-6000, USA.

E-mail: lasota@afip.osd.mil or jurek@erols.com

The opinions and assertions contained herein are the expressed views of the authors and are not to be construed as official or reflecting the views of the Departments of the Army or Defense. Received 31 May 2007; accepted 18 June 2007; published online 1 February 2008
Gastrointestinal stromal tumor (GIST) is the most common gastrointestinal, mesenchymal neoplasm driven by oncogenic activation of KIT or plateletderived growth factor receptor $\alpha$ (PDGFRA), a tyrosine kinase receptor. GISTs occur in different parts of GI tract and show a histological spectrum. Although spindle-cell morphology predominates, tumors with epithelioid or pleomorphic cell features 
also occur. Despite different histological appearances, KIT expression is seen in a great majority of GISTs. Biological potential of GISTs vary from indolent, benign tumors to highly malignant sarcomas. ${ }^{1}$

KIT and PDGFRA are members of type III tyrosine kinase receptor family. Activation of their signaling pathways is crucial for the development and maintenance of different cell populations including those of interstitial cells of Cajal, the GIST progenitor cells. $^{2}$

Initially, gain-of-function KIT mutations were found in a subset of GISTs; ${ }^{3}$ however, subsequent studies identified activating PDGFRA mutations in some KIT wild-type (WT) tumors. ${ }^{4}$ The majority of PDGFRA mutants represent gastric tumors with an epithelioid cell morphology. ${ }^{5}$

A great majority of KIT mutations affect exon 11, encoding the juxtamembrane domain; these include a spectrum of in-frame deletion/deletion-insertions, single nucleotide substitutions and duplications. In gastric tumors, the presence of KIT exon 11 deletion/deletion-insertions has been linked to more malignant clinical behavior. ${ }^{6}$ Also, it was shown that detection of Tyr557_Lys558del in gastric and other GISTs predicts unfavorable outcome. ${ }^{7,8}$

KIT extracellular domain mutations cluster in exon 9 and with rare exceptions represent duplication of six nucleotides leading to Ala502_Tyr503dup at the protein level. ${ }^{9}$ KIT exon 9 mutations occur almost exclusively in intestinal GISTs. ${ }^{10}$

In GISTs, KIT tyrosine kinase domain mutations have been identified in exon 13 encoding part of the first tyrosine kinase (TK1) domain (ATP-binding domain) and in exon 17 encoding part of the second tyrosine kinase (TK2) domain (enzymatic loop). Reported KIT exon 13 mutations consist of singlenucleotide substitutions, $1945 \mathrm{~A}>\mathrm{G}$ leading to Lys642Glu and KIT exon 17 mutations consist of either $2485 \mathrm{~A}>\mathrm{C}$ or $2487 \mathrm{~T}>\mathrm{A}$ substitutions, leading to Asn822Lys and Asn822His mutations, respectively. ${ }^{9,11}$

Imatinib mesylate is a tyrosine kinase inhibitor successfully used in the treatment of unresectable and metastatic GISTs. ${ }^{12,13}$ KIT-TK1 and -TK2 mutations have been only sporadically reported in untreated GISTs. ${ }^{10,14}$ However, these KIT domains are commonly affected by secondary mutations acquired during imatinib mesylate treatment and causing tumor resistance to this therapy. ${ }^{15}$

Although several KIT exon 13 and exon 17 mutants have been reported, ${ }^{8-11,14,16-25}$ complete demographic and clinicopathologic data have been provided only in a few cases. Thus, the clinicopathologic profile of tumors with such mutations is not known.

The purpose of this study was to evaluate frequency, morphologic features and natural history of GISTs with rare primary KIT exon 13 or exon 17 mutations and define the clinicopathologic profile of such tumors. To achieve this goal, several groups focused on GIST research participated in this study.

\section{Materials and methods}

Thirty-three GISTs with KIT exon 13 and 21 GISTs with KIT exon 17 mutations that were diagnosed before imatinib therapy were obtained from the files of the following organizations: the Armed Forces Institute of Pathology (AFIP), Washington, DC; Department of Pathology, Division of Hematology and Oncology, Oregon Health \& Science University Cancer Institute, Portland; VA Medical Center, Portland, OR; Department of Pathology, Catholic University of Leuven, Belgium; Department of Pathology, University of Bonn Medical Center, Bonn, Germany; Department of Pathology Jagiellonian University, Krakow, Poland; Department of Pathology, University Hospital Northern Norway, Tromsø, Norway; Department of Pathology, Memorial Sloan-Kettering Cancer Center, New York, NY; Department of Pathology, Medical Faculty Hospital, Charles University, Plzen, Czech Republic; Department of Oncology, Hospital Universitario de Son Dureta, Palma de Mallorca, Spain.

The tumors were diagnosed based on previously published criteria including morphologic and immunohistochemical features. ${ }^{1,15}$ Complete or partial clinicopathologic data were retrieved in 40 cases. Mitoses were counted in 50 high-power fields (HPFs), a total area of $5 \mathrm{~mm}^{2}$. Clinical follow-up data were obtained from the AFIP files or provided by contributors. Based on tumor size and mitotic activity, GISTs were classified into eight clinicopathologic prognostic groups as reported previously (Table 1). Prognostic comparative data were analyzed using Kruskal-Wallis test. All statistical tests were two sided and 5\% level of significance was used.

Table 1 Tumor size and mitotic criteria used to assess the malignant potential of GISTs, according to previously published studies

\begin{tabular}{|c|c|c|c|c|}
\hline \multirow[t]{2}{*}{ Group } & \multicolumn{2}{|c|}{ Tumor parameters } & \multicolumn{2}{|c|}{$\begin{array}{l}\text { Risk for metastasis (\% patients } \\
\text { with progressive disease) }\end{array}$} \\
\hline & Size $(\mathrm{cm})$ & $\begin{array}{l}\text { Mitosis/ } \\
50 \mathrm{HPFs}\end{array}$ & Gastric $^{\mathrm{a}}$ & Small intestinal ${ }^{\mathrm{b}}$ \\
\hline 1 & $\leq 2$ & $\leq 5$ & None & None \\
\hline 2 & $>2 \leq 5$ & $\leq 5$ & Low (1.9\%) & Low ( $4.3 \%)$ \\
\hline 3a & $>5 \leq 10$ & $\leq 5$ & Low $(3.6 \%)$ & Moderate $(24 \%)$ \\
\hline $3 \mathrm{~b}$ & $>10$ & $\leq 5$ & Moderate (12\%) & $\operatorname{High}(52 \%)$ \\
\hline 4 & $\leq 2$ & $>5$ & Unknown & High $(50 \%)$ \\
\hline 5 & $>2 \leq 5$ & $>5$ & Moderate (16\%) & High $(73 \%)$ \\
\hline $6 a$ & $>5 \leq 10$ & $>5$ & High $(55 \%)$ & High $(85 \%)$ \\
\hline $6 \mathrm{~b}$ & $>10$ & $>5$ & High $(86 \%)$ & High $(90 \%)$ \\
\hline
\end{tabular}

a Based on study on 1055 gastric GISTs. ${ }^{\circ}$

${ }^{b}$ Based on studies on 629 small intestinal GISTs. ${ }^{26}$ 
KIT mutation status was evaluated using methodologies previously published in the Department of Soft Tissue Pathology, AFIP, Washington, DC; Oregon Health \& Science University, Cancer Institute, Portland; VA Medical Center, Portland, OR; Department of Human Genetics, Catholic University of Leuven, Belgium; Department of Pathology, University of Bonn Medical Center, Bonn, Germany; Department of Pathology, Memorial Sloan-Kettering Cancer Center, New York, NY; Department of Pathology, Medical Faculty Hospital, Charles University, Plzen, Czech Republic; Department of Oncology, Hospital Universitario de Son Dureta, Palma de Mallorca, Spain.

Nomenclature of the KIT mutations identified at the DNA level and deduced KIT mutant sequences at the protein level are based on the recommendations of Human Genome Variation Society (www.hgvs.org). KIT reference sequence XO6182 was obtained from GeneBank at www.ncbi.nlm. nih.gov.

\section{Results}

\section{Molecular Studies}

Thirty-two (97\%) of 33 KIT exon 13 mutations were the $1945 \mathrm{~A}>\mathrm{G}$ substitution leading to Lys642Glu. In one tumor (Case 14), two substitutions, 1945A $>\mathrm{G}$ and $1948 \mathrm{G}>\mathrm{A}$, were identified leading to Lys642Glu and Val643Ile mutations, respectively. Two $(6.1 \%)$ of KIT exon 13 mutations reported in this study were homozygous by direct sequencing.

Fifteen $(71.4 \%)$ of 21 KIT exon 17 mutations represented $2487 \mathrm{~T}>\mathrm{A}$ substitution leading to Asn822Lys mutation. In one tumor (Case 11), variant substitution 2485A $>$ T leading to Asn822Tyr mutation was identified. Moreover, substitutions at codons $816(n=2), 820 \quad(n=2)$ and $823 \quad(n=1)$ leading to Asp816Phe, Asp816Tyr, Asp820Tyr, Asp820Val (Case 4) and Tyr823Asp, were also found in single cases. However, clinical data were not available for four cases with these mutations. All KIT mutations identified in exon 17 were heterozygous. Representative examples of direct sequencing of PCR products are shown in Figure 1.

\section{Demographic and Clinicopathologic Profile of KIT Exon 13 Mutant GISTs}

The demographic and clinicopathologic data of KIT exon 13 mutant GISTs are listed in Table 2. Age and sex of the patient were available for 26 cases. The ratio of men to women was 13:13, and median age was 67 . There were 2 esophageal, 10 gastric, 8 small intestinal, 2 colonic and 1 rectal GIST. In three cases, tumor location was unknown. Tumor size was available in 21 cases and varied from 1.2 to $25 \mathrm{~cm}$ (average $9.5 \mathrm{~cm})$. Ten $(47.6 \%)$ of 21 KIT exon 13 mutant tumors were $>5 \mathrm{~cm}$. Thirteen $(59.1 \%)$ of 22 analyzed tumors had $>5$ mitoses per 50 HPFs. Average tumor size and mitotic activity are listed in Table 3.

Based on tumor size and mitotic activity, two of eight gastric GISTs were considered to have a high risk $(>85 \%)$ of developing metastatic disease. However, one of these patients was alive without evidence of disease after 84 months of follow-up. Clinical observations documented GIST metastases in two other patients, one of which had a tumor with moderate risk features $(16 \%)$. Half of small intestinal GISTs were considered to have a high risk (50$90 \%$ ) of developing metastatic disease, and metastases were confirmed in two cases by follow-up. Another half represented tumors with no or low risk $(4.3-8.5 \%)$ of metastatic disease. Distribution of gastric and small intestinal tumors among prognostic groups is shown in Table 4.

The majority (18 of 22) of GISTs with KIT exon 13 mutations had a spindle-cell morphology. Two of four remaining tumors showed epithelioid features, while the other two had mixed spindle cell and epithelioid morphology with focal pleomorphism. Representative histological images are shown in Figure 1.

Immunohistochemically, KIT expression was seen in all analyzed cases $(n=18)$. CD34 was expressed in 15 of 16 analyzed tumors; however, in two cases only focally. SMA was expressed in 9 of 16 tumors; in most $(n=7)$ cases focally. One tumor showed coexpression of desmin and S-100 protein.

\section{Demographic and Clinicopathologic Profile of KIT Exon 17 Mutant GISTs}

The demographic and clinicopathologic data of KIT exon 17 mutant GISTs are listed in Table 5. Patient age and sex were available in 14 cases. The ratio of men to women was $6: 8$, and the median age was 64 . There were four gastric and eight small intestinal GISTs. In two cases, tumor location was unknown. Tumor size was recorded in 11 cases and varied from 2.5 to $18 \mathrm{~cm}$ (average $8.1 \mathrm{~cm}$ ). Seven $(63.6 \%$ ) tumors measured $>5 \mathrm{~cm}$. Histologic slides were available in 12 cases. All three gastric tumors and majority (five of six) of intestinal GISTs showed low mitotic activity, $<5$ mitosis/50 HPFs. Average tumor size and mitotic activity are listed in Table 3.

Based on tumor size and mitotic activity, three gastric tumors were considered to have a low risk $(1.9 \%)$ of developing metastatic disease. In two cases, benign behavior was confirmed by diseasefree follow-up of 13 and 16.6 years. However, three intestinal tumors were considered to have a high risk $(>50 \%)$ of metastatic disease. Two of these patients developed GIST metastases or died of GIST after 46 and 12 months, respectively; the third patient died of unknown causes after 24 months. Also, in one case in which full pathology parameters were not available for assessment of malignant 
642

C T C G A A G T C

a

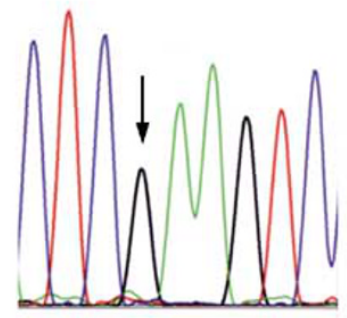

822

T C T A A N T A T

b

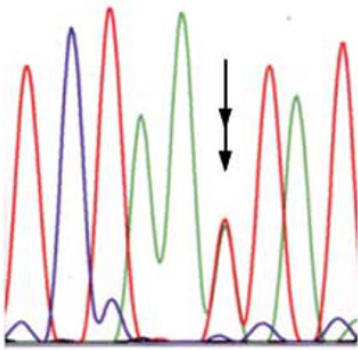

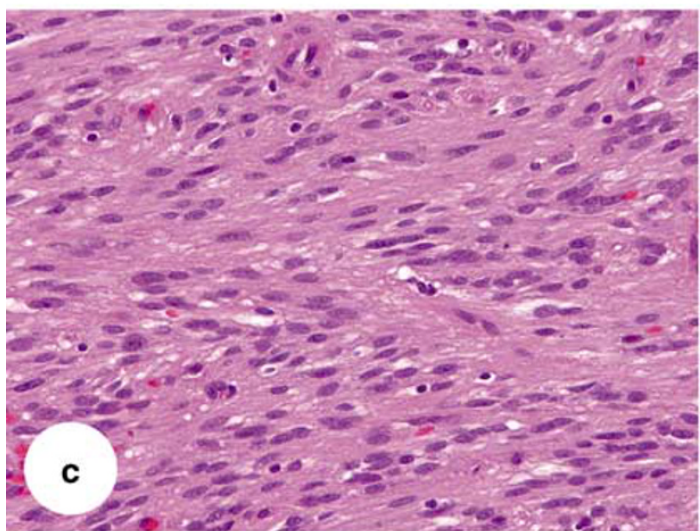
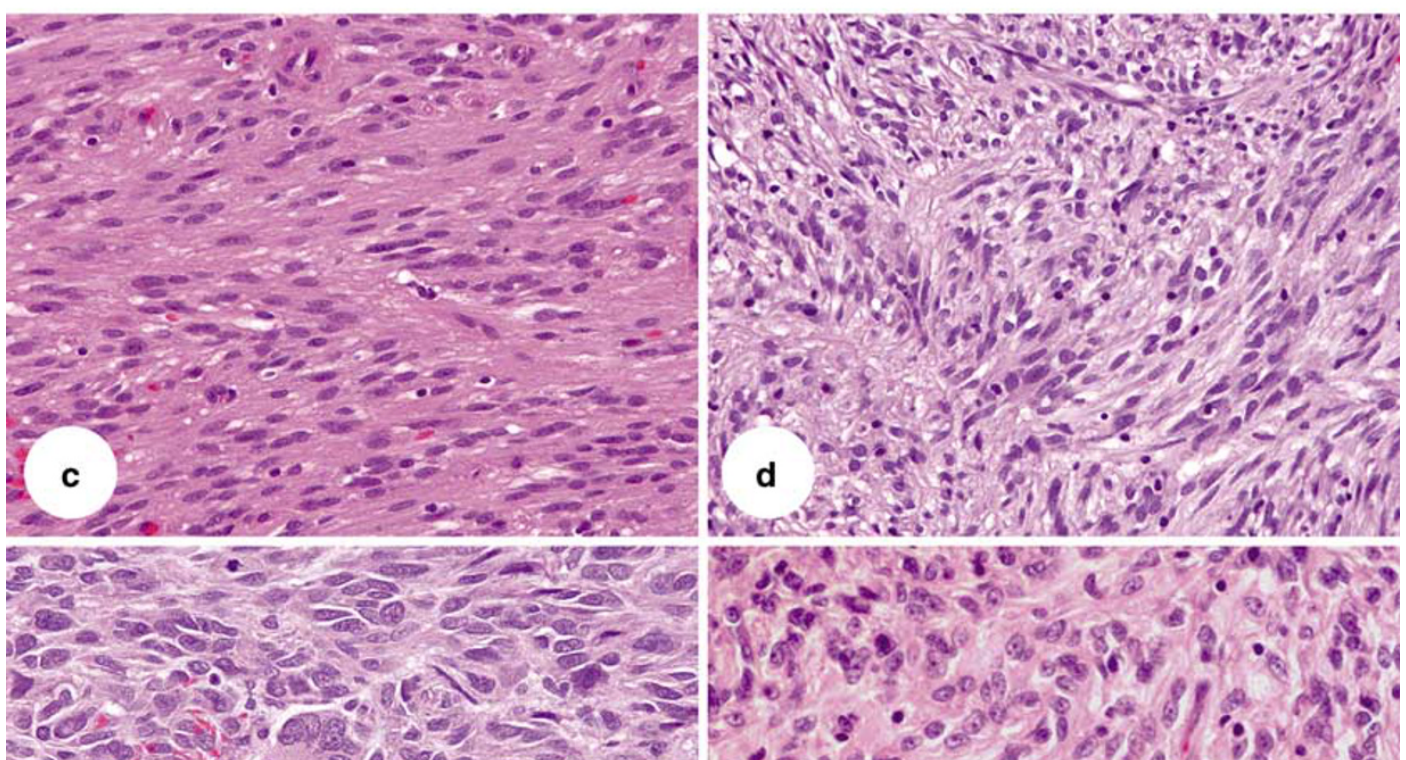

-0.0.
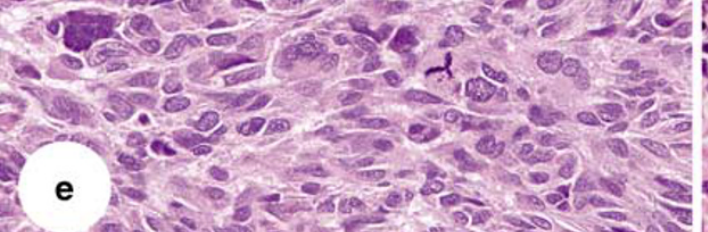

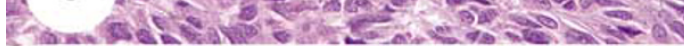
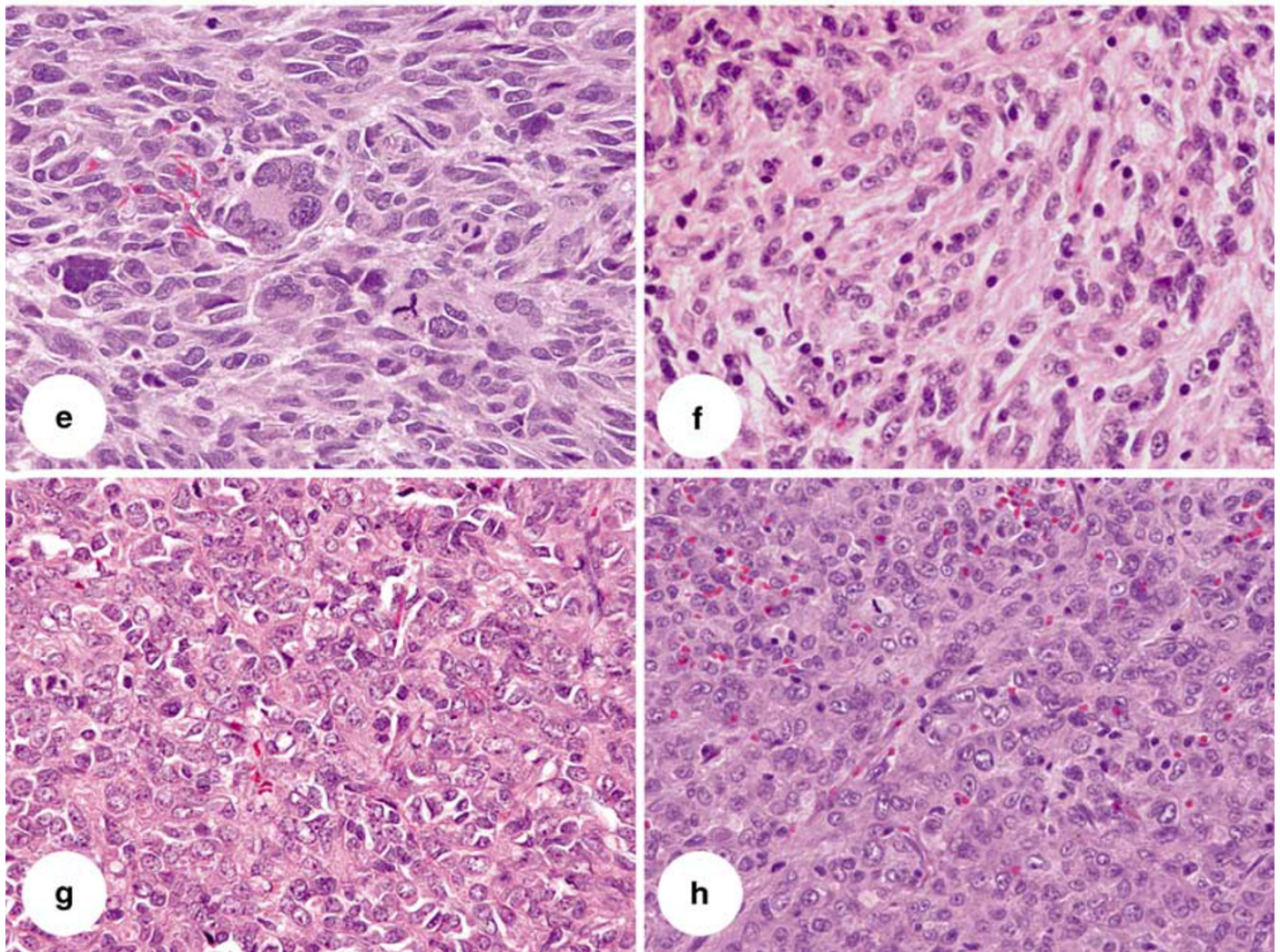

Figure 1 Example of direct sequencing of (a) KIT exon 13 and (b) KIT exon 17 mutant PCR amplification products in Case 13 and Case 10 ; single and double arrows indicate homozygous and heterozygous point mutations, respectively. Representative histological images of GISTs analyzed in this study. Benign spindle-cell GISTs (Case 20 and Case 3) with KIT exon 13 (c) and KIT exon 17 (d) mutations. Malignant spindle-cell GISTs (Case 10 and Case 6) with KIT exon 13 (e) and exon 17 (f) mutations. Malignant epithelioid GISTs (Case 14 and Case 12) with KIT exon 13 (g) and KIT exon 17 (h) mutations. 
Table 2 Summary of demographic and clinicopathologic data of 25 GISTs with primary KIT exon 13 mutations

\begin{tabular}{|c|c|c|c|c|c|c|c|c|}
\hline Case & Age & Sex & Location & Histology & Size $(\mathrm{cm})$ & $\begin{array}{l}\text { Mitosis/ } \\
50 \text { HPFs }\end{array}$ & $\begin{array}{l}\text { Group (risk of } \\
\text { MET in \%) }\end{array}$ & $\begin{array}{l}\text { Follw-up } \\
\text { (months) }\end{array}$ \\
\hline 1 & 70 & $\mathrm{~F}$ & Esophagus & Sp & 25 & 25 & 6b (90\%) & DOD 18 \\
\hline 2 & 62 & $\mathrm{~F}$ & Esophagus & UNK & 4 & UNK & UNK & UNK \\
\hline 3 & 60 & $\mathrm{~F}$ & Stomach & Sp & 30 & 4 & $3 \mathrm{~b}(12 \%)$ & DUNK 41 \\
\hline 4 & 73 & $\mathrm{~F}$ & Stomach & Sp & 15 & 16 & $6 \mathrm{~b}(86 \%)$ & UNK \\
\hline 5 & 66 & $\mathrm{~F}$ & Stomach & Sp & 10.5 & 17 & $6 \mathrm{~b}(86 \%)$ & ANED 84 \\
\hline 6 & 70 & $\mathrm{~F}$ & Stomach & Sp & 10 & 1 & 3а $(3.6 \%)$ & UNK \\
\hline 7 & 83 & $\mathrm{~F}$ & Stomach & $\mathrm{Sp}$ & 5 & 16 & $5(16 \%)$ & UNK \\
\hline 8 & 67 & $\mathrm{M}$ & Stomach & Sp & 4.3 & 0 & $2(1.9 \%)$ & UNK \\
\hline 9 & 70 & $\mathrm{M}$ & Stomach & Sp & 4 & 10 & $5(16 \%)$ & DUNC 71 \\
\hline 10 & 53 & $\mathrm{M}$ & Stomach & $\mathrm{Sp}+\mathrm{Ep}+\mathrm{Pl}$ & 3.5 & 52 & $5(16 \%)$ & IAB MET 6 \\
\hline 11 & 75 & $\mathrm{~F}$ & Stomach & $\mathrm{Sp}$ & UNK & 0 & UNK & UNK \\
\hline 12 & 76 & $\mathrm{~F}$ & Stomach & UNK & UNK & UNK & UNK & LIVER MET \\
\hline 13 & 64 & $\mathrm{M}$ & Small bowel & Sp & 20 & 13 & 6b (90\%) & DUNC 47 \\
\hline 14 & 28 & $\mathrm{M}$ & Small bowel & Ep & 18 & 0 & $3 b(52 \%)$ & IAB MET \\
\hline 15 & 39 & $\mathrm{~F}$ & Small bowel & $\mathrm{Sp}+\mathrm{Ep}+\mathrm{Pl}$ & 13.5 & 2 & $3 b(52 \%)$ & ANED 17 \\
\hline 16 & 39 & $\mathrm{M}$ & Small bowel & Ep & 8.5 & 30 & 6b (90\%) & LIVER MET 6 \\
\hline 17 & 67 & M & Small bowel & $\mathrm{Sp}$ & 4 & 0 & $2(4.3 \%)$ & ANED 99 \\
\hline 18 & 47 & $\mathrm{M}$ & Small bowel & UNK & 3.2 & 1 & $2(4.3 \%)$ & UNK \\
\hline 19 & 81 & $\mathrm{~F}$ & Small bowel & $\mathrm{Sp}$ & 1.5 & 0 & 1 (none) & UNK \\
\hline 20 & 52 & $\mathrm{~F}$ & Small bowel & Sp & 1.2 & 0 & 1 (none) & ADSU 108 \\
\hline 21 & 67 & $\mathrm{M}$ & Colon & Sp & 5 & 0 & $2(4.3 \%)$ & ADSU 120 \\
\hline 22 & 69 & $\mathrm{M}$ & Colon & Sp & UNK & 1 & UNK & DOD 48 \\
\hline 23 & 79 & $\mathrm{M}$ & Rectum & Sp & 5.5 & UNK & UNK & ANED 26 \\
\hline 24 & 62 & $\mathrm{~F}$ & UNK & $\mathrm{Sp}$ & 7 & 0 & 3a $\left(3.6 \_24 \%\right)$ * & UNK \\
\hline 25 & 55 & $\mathrm{M}$ & UNK & Sp & UNK & 20 & UN̄K & IAB MET \\
\hline 26 & 54 & $\mathrm{M}$ & UNK & UNK & UNK & UNK & UNK & IAB MET \\
\hline
\end{tabular}

Sp: spindle cell; Ep: epithelioid; Pl: pleomorphic; ADSU: alive disease status unknown; ANED: alive no evidence of disease; DOD: died of disease; DUNK: died of unknown causes; IAB: intraabdominal; MET: metastasis; UNK: unknown.

${ }^{*}$ Depends on tumor location.

Table 3 Mean tumor size and mitotic rate among gastric and small bowel GISTs with KIT exon 13 or exon 17 mutations

\begin{tabular}{|c|c|c|c|c|c|c|}
\hline \multirow[t]{2}{*}{ Mean } & \multicolumn{3}{|c|}{ KIT exon 13 mutants } & \multicolumn{3}{|c|}{ KIT exon 17 mutants } \\
\hline & All $(\mathrm{n}=21)$ & Gastric $(\mathrm{n}=8)$ & Small bowel $(\mathrm{n}=8)$ & All $(\mathrm{n}=11)$ & Gastric $(\mathrm{n}=3)$ & Small bowel $(\mathrm{n}=8)$ \\
\hline Tumor size (cm) & 9.5 & 11.1 & 8.7 & 8.1 & 3.7 & 9.7 \\
\hline Mitosis/50 HPF & 10 & 14 & 6 & 4 & $<1$ & 6 \\
\hline
\end{tabular}

potential, intraabdominal dissemination was diagnosed 56 months after surgery. Distribution of the tumors among prognostic groups is shown in Table 4.

Ten $(83 \%)$ of 12 KIT exon 17-mutant GISTs had a spindle-cell morphology. Predominant or focal epithelioid morphological cell features were seen in two intestinal tumors. Immunohistochemical KIT expression was documented in all analyzed tumors $(n=10)$. CD34 and SMA were expressed in five and six tumors, respectively. One tumor showed expression of S-100 protein.

\section{Frequency of KIT exon 13 and exon 17 Mutants}

Table 6 shows previously published data on the frequency of KIT exon 13 and exon 17 mutants. Cases from two clinical trials ${ }^{28,29}$ and two population-based studies ${ }^{20,25}$ were combined and the frequency was evaluated for each cohort. Both KIT exon 13 and exon 17 mutant GISTs appear to be slightly more frequent (1.6 and $1 \%$, respectively) among clinical trial patients than in populationbased patients ( 1.1 and $0.75 \%$, respectively). Overall, the frequency of KIT exon 13 and exon 17 mutants found in other non-trial-based studies was similar to that found in population-based studies. Based on our experience and published data, we conclude that the combined frequency of KIT exon 13 or exon 17 mutations among all GISTs is $1-2 \%$.

\section{Statistical Studies}

Risk of progressive disease in the cohorts of gastric or small intestinal GISTs with KIT exon 13 mutation and small intestinal GISTs with KIT exon 17 mutation was compared with risk of progressive disease in the cohorts of gastric or small intestinal 
Table 4 Distribution of KIT exon 13 and exon 17 mutant GISTs among eight prognostic groups and comparison of risk of progressive disease among GISTs with KIT exon 13 mutations versus all gastric or all small intestinal GISTs

\begin{tabular}{|c|c|c|c|c|c|c|}
\hline \multirow{2}{*}{$\begin{array}{l}\text { Prognostic } \\
\text { group }\end{array}$} & \multicolumn{3}{|c|}{ Gastric GIST } & \multicolumn{3}{|c|}{ Small intestinal GIST } \\
\hline & $\begin{array}{l}\text { KIT exon } 13 \\
\text { mutants }\end{array}$ & $\begin{array}{l}\text { KIT exon } 17 \\
\text { mutants }\end{array}$ & $A l l^{\mathrm{a}}$ & Exon 13 & Exon 17 & $A l l^{\mathrm{b}}$ \\
\hline 1 & & & $116(7.5 \%)$ & $2(25 \%)$ & & $69(8.7 \%)$ \\
\hline 2 & $1(11.1 \%)$ & $3(100 \%)$ & $456(29.4 \%)$ & $2(25 \%)$ & $1(16.7 \%)$ & $174(22 \%)$ \\
\hline $3 a$ & $1(11.1 \%)$ & & $301(19.4 \%)$ & & $2(33.3 \%)$ & $177(22.4 \%)$ \\
\hline $3 b$ & $1(11.1 \%)$ & & $193(12.4 \%)$ & $2(25 \%)$ & $2(33.3 \%)$ & $99(12.5 \%)$ \\
\hline 4 & & & $8(0.5 \%)$ & & & $2(0.3 \%)$ \\
\hline 5 & $3(33.3 \%)$ & & $137(8.8 \%)$ & & & $37(4.7 \%)$ \\
\hline $6 a$ & & & $153(9.9 \%)$ & $1(12.5 \%)$ & $1(16.7 \%)$ & $108(13.7 \%)$ \\
\hline $6 b$ & $3(33.3 \%)$ & & $188(12.1 \%)$ & $1(12.5 \%)$ & & $125(15.8 \%)$ \\
\hline Total: & 9 & 3 & 1552 & 8 & 6 & 791 \\
\hline
\end{tabular}

Risk of progressive disease was higher in gastric GISTs with KIT exon 13 mutations than in all gastric GISTs Significance:
$P=0.01$ (exon 13)

Not done (exon 17)
Risk of progressive disease was similar in different cohorts of small intestinal GISTs
$P=0.55$ (exon 13)

$P=0.62$ (exon 17)

${ }^{\mathrm{a}}$ Based on 1552 previously evaluated gastric GISTs. ${ }^{6}$

${ }^{\mathrm{b}}$ Based on 791 previously evaluated small intestinal GISTs. ${ }^{26}$

Table 5 Summary of demographic and clinicopathologic data of 25 GISTs with primary KIT exon 17 mutations

\begin{tabular}{|c|c|c|c|c|c|c|c|c|}
\hline Case & Age & Sex & $L O C$ & Histology & Size $(\mathrm{cm})$ & $\begin{array}{l}\text { Mitosis/ } \\
50 \text { HPFs }\end{array}$ & $\begin{array}{l}\text { Group (risk of } \\
\text { MET in \%) }\end{array}$ & $\begin{array}{l}\text { Follw-up } \\
\text { (months) }\end{array}$ \\
\hline 1 & 62 & $\mathrm{~F}$ & Stomach & Sp & 4.7 & 0 & $2(1.9 \%)$ & UNK \\
\hline 2 & 62 & M & Stomach & Sp & 4 & 1 & $2(1.9 \%)$ & DUNC 199 \\
\hline 3 & 64 & $\mathrm{~F}$ & Stomach & Sp & 2.5 & 0 & $2(1.9 \%)$ & ADSU 156 \\
\hline 4 & 80 & $\mathrm{~F}$ & Stomach & Sp & UNK & 1 & UNK & UNK \\
\hline 5 & 49 & $\mathrm{M}$ & Small bowel & Sp & 18 & 3 & $3 b(52 \%)$ & DOD 12 \\
\hline 6 & 64 & $\mathrm{~F}$ & Small bowel & $\mathrm{Sp}$ & 16 & 4 & $3 b(52 \%)$ & DUNK 24 \\
\hline 7 & 77 & $\mathrm{M}$ & Small bowel & UNK & 10 & UNK & UNK & IAB MET 56 \\
\hline 8 & 46 & $\mathrm{~F}$ & Small bowel & $\mathrm{Sp}$ & 8.3 & UNK & UNK & DUNK 36 \\
\hline 9 & 64 & $\mathrm{~F}$ & Small bowel & Sp+Ep & 8 & 0 & 3a $(24 \%)$ & UNK \\
\hline 10 & 50 & $\mathrm{M}$ & Small bowel & Sp & 6.2 & 4 & 3a $(24 \%)$ & ANED 170 \\
\hline 11 & 71 & $\mathrm{~F}$ & Small bowel & Sp & 3 & 0 & $2(4.3 \%)$ & ANED 67 \\
\hline 12 & 61 & M & $\begin{array}{l}\text { Small bowel/ } \\
\text { Mesenterium }\end{array}$ & Ep & 8 & 25 & $6 a(85 \%)$ & IAB MET 46 \\
\hline 13 & 44 & $\mathrm{~F}$ & IAB & UNK & UNK & UNK & UNK & UNK \\
\hline 14 & 65 & $\mathrm{M}$ & IAB & $\mathrm{Sp}$ & UNK & 8 & UNK & UNK \\
\hline
\end{tabular}

Sp: spindle cell; Ep: epithelioid; Pl: pleomorphic; ADSU: alive disease status unknown; ANED: alive no evidence of disease; DOD: died of disease; DUNK: died of unknown causes; IAB: intraabdominal; MET: metastasis; UNK: unknown.

GISTs without determined mutational status. Cohorts of gastric and small intestinal GISTs without determined mutational status were taken from previously published studies. ${ }^{6,26}$

All results of statistical studies are shown in Table 4. A risk of progressive disease was higher in gastric GISTs with KIT exon 13 mutation than in gastric GISTs without determined mutational status.

\section{Discussion}

Although KIT tyrosine kinase domain mutations are very rare in GISTs, our multicenter collaboration involving several groups of GIST researchers from the US and Europe allowed us to collect a significant number of KIT exon $13(n=33)$ and exon $17(n=21)$ mutant GIST and study their $(n=40)$ clinicopathologic profile.

Initially, a Lys642Glu mutation was reported in two $(25 \%)$ of eight GISTs that lacked KIT exon 11 mutations and was shown to cause constitutive KIT tyrosine phosphorylation. ${ }^{9}$ A family with germline Lys642Glu mutation developing multiple GISTs was reported subsequently. ${ }^{30}$ Recently, a mouse model reproducing human familial GIST syndrome with inherited Lys642Glu mutation has been developed. ${ }^{31}$

In this study, almost all (32 of 33) KIT exon 13 mutants had an identical 1945A $>$ G substitution leading to Lys642Glu mutation, and two substitutions $1945 \mathrm{~A}>\mathrm{G}$ and $1948 \mathrm{G}>\mathrm{A}$ leading to 
Table 6 Frequency of KIT codon 642 and codon 822 mutations in GISTs in previously reported major studies

\begin{tabular}{|c|c|c|c|c|c|}
\hline \multirow[t]{2}{*}{ Source of material } & \multirow[t]{2}{*}{ Study } & & \multirow[t]{2}{*}{ No. of cases } & \multicolumn{2}{|c|}{ KIT mutant } \\
\hline & & & & Lys642Glu & $\begin{array}{l}\text { Asn822Lys } \\
\text { Asn822His }\end{array}$ \\
\hline \multirow{10}{*}{$\begin{array}{l}\text { Cancer Center, Consultation } \\
\text { Center or University Hospital }\end{array}$} & Lasota et $a l^{5}$ & US/Finland & 200 & $2(1.0 \%)$ & Not studied \\
\hline & Rubin et $a l^{11}$ & US & 48 & $2(4.2 \%)$ & $2(4.2 \%)$ \\
\hline & Wardelmann et a ${ }^{16}$ & Germany & 36 & $1(2.8 \%)$ & $\begin{array}{c}0 \\
0\end{array}$ \\
\hline & Antonescu et $a l^{27}$ & US & 120 & 0 & 0 \\
\hline & Kinoshita et $a l^{14}$ & Japan & 141 & $1(0.7 \%)$ & 0 \\
\hline & He et $a l^{23}$ & China & 155 & $1(0.7 \%)$ & $1(0.6 \%)$ \\
\hline & Daum et $a l^{24}$ & Czech & 60 & $1(1.7 \%)$ & 0 \\
\hline & Cho et $a l^{21}$ & Japan & 69 & $1(1.5 \%)$ & 0 \\
\hline & Cho et $a 1^{22}$ & & & & \\
\hline & Subtotal: & & $829 / 629$ & $9(1.1 \%)$ & $3(0.5 \%)$ \\
\hline \multirow[t]{3}{*}{ Imatinib mesylate clinical trial } & Heinrich et $a l^{4}$ & US & 127 & $2(1.6 \%)$ & $2(1.6 \%)$ \\
\hline & Debiec-Rychter et $a l^{28}$ & Europe & 377 & $6(1.6 \%)$ & $3(0.8 \%)$ \\
\hline & Subtotal: & & 504 & $8(1.6 \%)$ & $5(1 \%)$ \\
\hline \multirow[t]{3}{*}{ Population based } & Andersson et $a l^{20}$ & Sweden & 177 & 0 & $1(0.6 \%)$ \\
\hline & Steigen et $a l^{25}$ & Norway & 89 & $3(3.4 \%)$ & $1(1.1 \%)$ \\
\hline & Subtotal: & & 266 & $3(1.1 \%)$ & $2(0.75 \%)$ \\
\hline
\end{tabular}

Lys642Glu and Val643Ile were seen only in one case. More recently, two groups reported four KIT exon 13 mutations clustering in the vicinity of codon 642 in primary GISTs. These mutations consisted of singleamino acid substitutions Leu641Pro, Val643Ala, Leu647Pro and Met651Val. Constitutive KIT tyrosine phosphorylation by these mutations has not been documented. ${ }^{21-23}$ Three of these mutations were identified in a relatively small cohort of 69 patients resulting in a surprisingly high frequency of unusual mutants. ${ }^{22,23}$

The first two KIT exon 13 mutations reported in GISTs were homozygous by direct sequencing; however, results of fluorescence in situ hybridization (FISH) and loss of heterozygosity (LOH) studies suggested duplication of the mutant KIT allele in those cases. ${ }^{9}$ Also, a recent large study on homozygous KIT exon 11 mutations showed that a loss of KIT-WT is followed by a duplication of KIT-MT allele. $^{32}$ Thus, different homozygous mutations might have a similar universal molecular mechanism in GISTs. In this study, homozygous KIT exon 13 mutations were found in $2(6.1 \%)$ of 33 cases. Both GISTs with homozygous KIT exon 13 mutations were malignant tumors with moderate $(16 \%)$ to high $(90 \%)$ risk of metastatic disease. A malignant clinical behavior was also reported in majority of homozygous KIT exon 11 GIST mutants. ${ }^{32}$

In sporadic GISTs, previously reported KIT exon 17 mutations involved exclusively codon $822 .{ }^{11,18} \mathrm{In}$ this study, several exceptions were found showing that some GISTs have KIT exon 17 mutations similar to those more commonly associated with mastocytosis and urticaria pigmentosa, gonadal germ cell tumors of seminoma/dysgerminoma type, mediastinal seminomas and sinonasal natural killer/T-cell lymphomas. ${ }^{33}$ An Asp820Tyr mutation previously identified in familial GIST syndrome ${ }^{30}$ was also found in one case.

KIT exon 11 mutations have been found in GISTs from different locations. However, duplications in the $3^{\prime}$ part of KIT exon 11 have shown a predilection to gastric tumors with spindle-cell morphology. ${ }^{34}$ Also, various PDGFRA mutations have been found mostly in gastric GISTs, especially those with epithelioid morphology. ${ }^{5,35}$ In contrast, a great majority of Ala502_Tyr503dup mutants have been reported in intestinal tumors. ${ }^{27,36}$ In this study, KIT exon 13 and exon 17 mutations showed a predilection to GISTs of intestinal and small intestinal location, respectively. It is possible that GISTs showing predilection to different GI-tract locations might develop from different subsets of interstitial cell of Cajal. ${ }^{37}$

A great majority of KIT exon 13 and exon 17 mutant GISTs had spindle-cell morphology. However, three malignant small intestinal tumors showed predominantly epithelioid morphological features. Recent study based on 906 GISTs suggested that epithelioid cell features seen in small intestinal tumors might represent malignant transformation. ${ }^{26}$

All KIT tyrosine kinase mutants expressed KIT; however, almost all tumors with KIT exon 13 mutations coexpressed CD34. Previously, CD34 expression was documented in $82 \%$ of gastric tumors but only in $40 \%$ of small intestinal ones. ${ }^{1}$

The frequency of KIT exon 13 (Lys642Glu) and exon 17 (Asn822Lys) mutations varies between 1 
and $2 \%$ in most studies (Table 6). An apparently higher frequency $(2.5-4 \%)$ of these mutations was reported in three studies based on GIST cohorts smaller than 100 cases. ${ }^{11,16,25}$ Thus, these results might represent random statistical variations. Also, there were no significant differences in frequency of KIT exon 13 or exon 17 mutations in GISTs from oncologic trials ${ }^{28,29}$ and population-based studies. ${ }^{20,25}$ A Slightly higher frequency of KIT exon 13 and exon 17 mutations in GISTs from clinical trials might be related to increased number of intestinal GISTs in such trials, which in general follow more malignant course of disease and are overrepresented among KIT exon 13 and exon 17 mutants.

Previous studies showed that some type of KIT mutations could be linked to malignant behavior. For example, gastric GISTs with KIT exon 11 deletions follow a more malignant course of disease than the ones with point mutations. ${ }^{6}$ Also, the presence of Tyr557_Lys558del was linked to unfavorable GIST clinical outcome. ${ }^{7,8}$ An Ala502_Tyr503dup, exclusively seen in small intestinal tumors, was initially associated with poor outcome, when GISTs from different locations were analyzed. ${ }^{27,36}$ However, comparison between small intestinal GISTs with KIT exon 11 mutations and tumors with KIT exon 9 mutations did not show a significant difference in clinical behavior suggesting that association between Ala502_Tyr503dup and malignant outcome was consequence of more malignant behavior of small intestinal GISTs than gastric tumors. ${ }^{26}$

In this study, a link between KIT exon 13 or exon 17 mutations and malignant clinical behavior could not be established in small bowel tumors probably contributed by incomplete pathology parameters and relatively small number of cases. However, tumors with moderate or high risk of metastases predominated among gastric GISTs with KIT exon 13 mutations.

Imatinib mesylate, a KIT and PDGFRA tyrosine kinase inhibitor has been used successfully for a treatment of unresectable and metastatic GISTs. ${ }^{12,13}$ Patients with KIT exon 11 mutant GISTs are more likely to achieve a partial response to imatinib mesylate treatment than those with tumors harboring other KIT mutations. ${ }^{15,28,29}$ Although in vitro studies suggested inhibition of KIT Lys642Glu oncoprotein by imatinib mesylate ${ }^{38}$ clinical data are limited, because KIT exon 13 or exon 17 mutant GISTs are extremely rare.

Three previous studies identified partial response and stable disease in seven and two patients with KIT exon 13 mutant GISTs, respectively. ${ }^{27-39}$ In this study, one GIST (Case 16) not included in the previous series, showed slow progression on imatinib mesylate treatment (Martin J, personal communication). In patients with KIT exon 17 mutant GISTs, partial response or stable disease and progressive disease was seen in 4 and 1 cases, respectively. ${ }^{28,29}$
GISTs can acquire resistance to the imatinib during a treatment and such resistance has been linked to secondary KIT or PDGFRA mutations. Secondary KIT mutations affect exons 13 and 14 in KIT-TK1 and exon 17 in KIT-TK2 domains, respectively. Primary and secondary mutations in KIT-TK1 domain affect different codons. In contrast, the primary and secondary mutations in KIT exon 17 cluster in the same 'hot spots'. ${ }^{40}$

In summary, we have defined the clinicopathologic profile of GISTs with primary mutations in KIT tyrosine kinase domains. The frequency of such tumors among all GISTs is no higher than 1-2\%. Generally, these tumors show spindle-cell morphology and a predilection for the small intestine. KIT exon 13 mutant gastric GISTs tend to be significantly more aggressive than gastric GISTs in average, whereas gastric GISTs with KIT exon 17 mutations did not show any similar tendency. However, the behavior of small intestinal GISTs with KIT exon 13 or exon 17 mutations does not differ from other small intestinal GISTs.

\section{References}

1 Miettinen M, Lasota J. Pathology and prognosis of gastrointestinal stromal tumors at different sites. Semin Diagn Pathol 2006;23:70-83.

2 Kitamura Y, Hirota S. Kit as human oncogenic tyrosine kinase. Cell Mol Life Sci 2004;61:2924-2931.

3 Hirota S, Isozaki K, Moriyama Y, et al. Gain-of-function mutations of c-kit in human gastrointestinal stromal tumors. Science 1998;279:577-580.

4 Heinrich MC, Corless CL, Duensing A, et al. PDGFRA activating mutations in gastrointestinal stromal tumors. Science 2003;299:708-710.

5 Lasota J, Dansonka-Mieszkowska A, Sobin LH, et al. A great majority of GISTs with PDGFRA mutations represents gastric tumors of low or no malignant potential. Lab Invest 2004;84:874-883.

6 Miettinen M, Sobin LH, Lasota J. Gastrointestinal stromal tumors (GISTs) of the stomach-a clinicopathologic, immunohistochemical and molecular genetic study of 1756 cases with long-term follow-up. Am J Surg Pathol 2005;29:52-68.

7 Wardelmann E, Losen I, Hans V, et al. Deletion of Trp-557 and Lys-558 in the juxtamembrane domain of the c-kit protooncogene is associated with metastatic behavior of gastrointestinal stromal tumors. Int J Cancer 2003;106:887-895.

8 Martin J, Poveda J, Llombart-Bosch A, et al. Deletions affecting codons 557-558 of the $C$-KIT gene indicate a poor prognosis in patients with completely resected gastrointestinal stromal tumors: a study by the Spanish Group for Sarcoma Research (GEIS). J Clin Oncol 2005;23:6190-6198.

9 Lux ML, Rubin BP, Biase TL, et al. KIT extracellular and kinase domain mutations in gastrointestinal stromal tumors. Am J Pathol 2000;156:791-795.

10 Lasota J, Wozniak A, Sarlomo-Rikala $\mathrm{M}$, et al. Mutations in exons 9 and 13 of KIT gene are rare events in gastrointestinal stromal tumors. A study of two hundred cases. Am J Pathol 2000;157:1091-1095. 
11 Rubin BP, Singer S, Tsao C, et al. KIT activation is a ubiquitous feature of gastrointestinal stromal tumors. Cancer Res 2001;61:8118-8121.

12 Joensuu H, Roberts PJ, Sarlomo-Rikala M, et al. Effect of tyrosine kinase inhibitor STI571 in a patient with a metastatic gastrointestinal stromal tumor. N Engl J Med 2001;344:1052-1056.

13 Demetri GD. Identification and treatment of chemoresistant inoperable or metastatic GIST: experience with the selective tyrosine kinase inhibitor imatinib mesylate (STI571). Eur J Cancer 2002;38(Suppl 5):S52-S59.

14 Kinoshita $\mathrm{K}$, Isozaki $\mathrm{K}$, Hirota $\mathrm{S}$, et al. c-kit gene mutation at exon 17 and 13 is very rare in sporadic gastrointestinal stromal tumors. J Gastroenterol Hepatol 2003;18:147-151.

15 Corless CL, Fletcher JA, Heinrich MC. Biology of gastrointestinal stromal tumors. J Clin Oncol 2004;22:3813-3825.

16 Wardelmann E, Neidt I, Bierhoff E, et al. c-kit mutations in gastrointestinal stromal tumors occur preferentially in the spindle rather than in the epithelioid cell variant. Mod Pathol 2002;15:125-136.

17 Subramanian S, West R, Corless CL, et al. Gastrointestinal stromal tumors (GISTs) wit KIT and PDGFRA mutations have distinct gene expression profiles. Oncogene 2004;23:7780-7790.

18 Wasag B, Debiec-Rychter M, Pauwels P, et al. Differential expression of KIT/PDGFRA mutant isoforms in epithelioid and mixed variants of gastrointestinal stromal tumors depends predominantly on the tumor site. Mod Pathol 2004;17:889-894.

19 Pauls K, Merkelbach-Bruse S, Thal D, et al. PDGFR $\alpha-$ and c-kit-mutated gastrointestinal stromal tumours (GISTs) are characterized by distinctive histological and immunohistochemical features. Histopathology 2005;46:166-175.

20 Andersson J, Bumming P, Meis-Kindblom JM, et al. Gastrointestinal stromal tumors with KIT exon 11 deletions are associated with poor prognosis. Gastroenterology 2006;130:1573-1581.

21 Cho S, Kitadai Y, Yoshida S, et al. Deletion of the KIT gene is associated with liver metastasis and poor prognosis in patients with gastrointestinal stromal tumor in the stomach. Int J Oncol 2006;28:1361-1367.

22 Cho S, Kitadai Y, Yoshida S, et al. Genetic and pathologic characteristics of gastrointestinal stromal tumors in extragastric lesions. Int J Mol Med 2006;18: 1067-1071.

23 He HY, Fang WG, Zhong HH, et al. Status and clinical implication of c-kit and PDGFRA mutations in 165 cases of gastrointestinal stromal tumor (GIST). Zhonghua Bing Li Xue Za Zhi 2006;35:262-266.

24 Daum O, Grossmann P, Vanecek T, et al. Diagnostic morphological features of PDGFRA-mutated gastrointestinal stromal tumors: molecular genetic and histologic analysis of 60 cases of gastric gastrointestinal stromal tumors. Ann Diagn Pathol 2007;11:27-33.

25 Steigen SE, Eide TJ, Wasag B, et al. Mutations in gastrointestinal stromal tumors-a population based study from northern Norway. APMIS 2007;115: 289-298.

26 Miettinen M, Makhlouf H, Sobin LH, et al. Gastrointestinal stromal tumors (GISTs) of the jejunum and ileum: a clinicopathologic, immunohistochemical and molecular genetic study of 906 cases before imatinib with long-term follow-up. Am J Surg Pathol 2006;30:477-489.

27 Antonescu CR, Sommer G, Sarran L, et al. Association of KIT exon 9 mutation with nongastric primary site and aggressive behavior: KIT mutation analysis and clinical correlates of 120 gastrointestinal stromal tumors. Clin Cancer Res 2003;9:3329-3337.

28 Debiec-Rychter M, Sciot R, Le Cesne A, et al. KIT mutations and dose selection for imatinib in patients with advanced gastrointestinal stromal tumours. Eur J Cancer 2006;42:1093-1103.

29 Heinrich MC, Corless CL, Demetri GD, et al. Kinase mutations in imatinib response in patients with metastatic gastrointestinal stromal tumor. J Clin Oncol 2003;21:4342-4349.

30 Isozaki K, Terris B, Belghiti J, et al. Germline-activating mutation in the kinase domain on KIT gene in familial gastrointestinal stromal tumors. Am J Pathol 2001;157: 1581-1585.

31 Rubin BP, Antonescu CR, Scott-Browne JP, et al. A knock-in mouse model of gastrointestinal stromal tumor harboring Kit K641E. Cancer Res 2005;65: 6631-6639.

32 Lasota J, Jerzak vel Dobosz A, Wasag B, et al. Presence of homozygous KIT exon 11 mutations is strongly associated with malignant clinical behavior in gastrointestinal stromal tumors. Lab Invest 2007;87: 1029-1041.

33 Miettinen M, Lasota J. KIT (CD117)—a review on expression in normal and neoplastic tissues, and mutations and their clinicopathologic correlation. Appl Immunohistochem Mol Morphol 2005;13: 205-220.

34 Lasota J, Dansonka-Mieszkowska A, Stachura T, et al. Gastrointestinal stromal tumors with internal tandem duplications in $3^{\prime}$ end of KIT juxtamembrane domain occur redominantly in stomach and generally seem to have a favorable course. Mod Pathol 2003;16: 1257-1264.

35 Wardelmann E, Hrychyk A, Markelbach-Bruse S, et al. Association of platelet-derived growth factor receptor $\alpha$ mutations with gastric primary site and epithelioid or mixed cell morphology in gastrointestinal stromal tumors. J Molec Diagnostics 2004;6: 197-204.

36 Lasota J, Kopczynski J, Sarlomo-Rikala M, et al. KIT 1530ins6 mutation defines a subset of predominantly malignant gastrointestinal stromal tumors of intestinal origin. Human Pathol 2003;34:1306-1312.

37 Rumessen JJ, Thuneberg L. Pacemaker cells in the gastrointestinal tract: interstitial cells of Cajal. Scand J Gastroenterol Suppl 1996;216:82-94.

38 Tuveson DA, Willis NA, Jacks T, et al. STI571 inactivation of the gastrointestinal stromal tumor c-KIT oncoprotein: biological and clinical implications. Oncogene 2001;20:5054-5058.

39 Antonescu CR, Besmer P, Guo T, et al. Acquired resistance to imatinib in gastrointestinal stromal tumor occurs through secondary gene mutation. Clin Cancer Res 2005;11:4182-4190.

40 Lasota J, Miettinen M. KIT and PDGFRA mutations in gastrointestinal stromal tumors (GISTs). Semin Diagn Pathol 2006;23:91-102. 